Bohunovsky, R. - Perturbação

\title{
A Perturbação, de Thomas Bernhard, em português: duas traduções em comparação
}

\author{
[Perturbação, by Thomas Bernard, in Portuguese: comparing two translations]
}

\author{
Ruth Bohunovsky ${ }^{1}$
}

\begin{abstract}
In this article, we compare two translations of the novel Verstörung (first published in German in 1967) by the Austrian writer Thomas Bernhard: the Portuguese translation (1986, by Leopoldina Almeida) and the Brazilian translation (1999, by Hans Peter Welper and José Laurenio de Melo). The article is based on the premise that Verstörung is a book with a strong performative dimension; the disturbance which names the book is not only represented in the plot and the characterization of the characters, but also - and especially - in the style, in the language of the German text. We discuss and compare different solutions of translations in the Portuguese versions, as well as the paratexts contained in the two publications. We found two different postures in dealing with the specifics of the language in this novel, both with consequences for their performative effect. Finally, we suggest that these attitudes can be seen as reflections of different moments of literary criticism in relation to Thomas Bernhard.
\end{abstract}

Keywords: Thomas Bernhard, literary translation, reception.

Resumo: Neste artigo, comparamos duas traduções em língua portuguesa do romance Verstörung (primeira edição em língua alemã em 1967) do escritor austríaco Thomas Bernhard: a tradução portuguesa (1986, por Leopoldina Almeida) e a brasileira (1999, por Hans Peter Welper e José Laurenio de Melo). Partimos da premissa de que Verstörung é um livro com uma dimensão performativa acentuada, ou seja, a perturbação que dá nome ao livro não está representada apenas no enredo e na caracterização dos personagens, mas também - ou sobretudo - no estilo, na linguagem do texto em alemão. Discutimos e comparamos diferentes soluções tradutórias nas referidas versões em português, assim como os paratextos que constam nas duas publicações. Constatamos duas posturas divergentes ao lidar com as especificidades da linguagem da obra, ambas com consequências para o seu efeito performativo. Por fim, sugerimos que essas posturas possam ser reflexos das diferenças da própria crítica literária em relação a Thomas Bernhard em dois momentos diversos.

Palavras-chave: Thomas Bernhard, tradução literária, recepção.

\footnotetext{
${ }^{1}$ Doutora em Linguística Aplicada (Tradução) pela Universidade Estadual de Campinas (UNICAMP); professora adjunta III na Universidade Federal do Paraná (UFPR). Email: ruth.bohunovsky@uol.com.br.
} 
Bohunovsky, R. - Perturbação

\section{A tradução literária como transformação esclarecedora}

De acordo com teorias atuais, uma tradução é entendida como uma reescrita ou até mesmo como um comentário acerca de um texto original, nunca como sua cópia fiel. Esse fato pode ser avaliado de diferentes maneiras. Thomas Bernhard, no seu costumeiro estilo radical e hiperbólico, foi enfático ao dizer que um livro traduzido é "do tradutor", não mais do autor, "não é mais reconhecível"2. Para Bernhard, "Um livro traduzido é como um homem morto, que foi mutilado e totalmente desfigurado por um carro" (In: MonOlOGE 2008). No entanto, essa "mutilação" do original, esse "homem morto" desfigurado é justamente o que permite a sobrevida de literatura e, consequentemente, o que permitiu a transformação de Thomas Bernhard de escritor e provocador austríaco em autor de livros considerados parte da Weltliteratur, do cânone literário internacional.

Obviamente, existem visões mais positivas do que a de Bernhard sobre tradução e a sua inevitável manipulação do texto original. Sem querer retomar discussões teóricas de várias décadas, neste artigo destaco apenas o crescente interesse da germanística austríaca em relação às leituras de Bernhard mundo afora. Tais leituras - nas suas formas de tradução, de crítica ou de recepção produtiva - teriam permitido que se tivesse acesso a "divergências esclarecedoras dos nossos mecanismos rotineiros de interpretação", como aponta Wolfram BAYER na introdução da coletânea Kontinent Bernhard: zur ThomasBernhard-Rezeption in Europa (1995: 9). No exterior, a dimensão política e as leituras realistas que prevaleciam na recepção primária austríaca e nos outros países de língua alemã foram substituídas muitas vezes por um enfoque maior nos aspectos estéticos e formais da linguagem bernhardiana (BAYER 1995: 10). O potencial político, porém, nem sempre se perdeu. Isso vale, por exemplo, para a França e a Espanha, e também para a Polônia, onde, de acordo com a tradutora Slawa Lisiecka, responsável pelas traduções da obra de Bernhard naquele país, o escritor austríaco pode ser considerado quase um sucessor de Witold Gombrowicz. De acordo com LISIECKA, "um dos motivos para isso deve-se [ao fato] de depois de Witold Gombrowicz não termos tido nenhum escritor tão importante que escreva uma literatura tão crítica em relação à sua nação e que trate da sua

\footnotetext{
${ }^{2}$ Essa tradução, assim como todas as outras de obras não traduzidas para o português, é minha.
} 


\section{Bohunovsky, R. - Perturbação}

tradição e do seu mito" (2012: 2). No livro Kontinent Bernhard, BAYER fala de um “acesso mais desembaraçado" (1995: 9) de leitores e críticos de outras línguas em relação aos germanistas austríacos - que, querendo ou não, fazem parte justamente do públicoalvo das injúrias e acusações do mais famoso Nestbeschmutzer (aquele que suja o próprio ninho) de língua alemã. De um modo geral, as diversas recepções confirmariam algo que já se mostrava nos impactos históricos dos livros de Bernhard no âmbito do seu país de origem, isto é, o "caráter contraditório" desse autor. Dependendo do contexto, ele é entendido como "escritor rural ou dândi", "como niilista ou humanista, como 'diretor do estado' ou outsider, como escritor nacional ou poeta excluído, como venerador de Maria ou como depravador de almas, como anjo da morte ou como salvador da vida" (BAYER 1995: 12).

A recepção da obra de Thomas Bernhard passou por várias fases - tanto no âmbito dos países de língua alemã quanto em outros contextos. De um modo geral, podese resumir que, enquanto Bernhard ainda estava vivo (ele faleceu em 1989), a crítica se concentrou primordialmente na relação da sua literatura com o Estado da Áustria, o que lhe gerou a fama de Nestbeschmutzer. Sua obra foi lida frequentemente como literatura realista, a comparação entre a suposta realidade austríaca e a sua representação nos textos marcou discussões e debates teóricos. Mais tarde, enfatizou-se cada vez mais a singularidade formal da sua obra, sua musicalidade, e, ultimamente, tem-se destacado seu humor e as facetas cômicas ${ }^{3}$. Se o potencial para interpretações heterogêneas está, por um lado, nos próprios textos, por outro, a história da recepção e da tradução da obra de Bernhard certamente contribui para evidenciar a multiplicidade das possíveis leituras desse escritor.

As traduções dos livros de Thomas Bernhard têm sido alvo de inúmeras análises e avaliações. Interessa-nos aqui menos uma abordagem normativa seguindo um determinado modelo de avaliação de traduções literárias como aquele proposto por Christiane BÖHLER (2002), cujo foco principal segue sendo a ideia de uma suposta "perda" que envolve qualquer tradução em relação ao original ou a uma leitura tida como a única válida. Seguimos mais o raciocínio de Gitta HoNEGGER (2010), que se distancia

\footnotetext{
${ }^{3}$ Cf., por exemplo, PECKA (2009) e os diversos artigos sobre a recepção da literatura de Thomas Bernhard em BAYER (1995).
} 


\section{Bohunovsky, R. - Perturbação}

de uma avaliação explícita das traduções e aborda os efeitos da linguagem - no original e em traduções de língua inglesa - sobre a figura do narrador em alguns títulos representativos de Bernhard. Ela conclui, por exemplo, que, no caso de Beton (ainda sem tradução no Brasil), a versão em inglês de David McLintock transforma "os excessos do barroco austríaco de autoindulgência" em uma linguagem "rígida" de um "aristocrata inglês" (HONEGGER 2010: 171); o narrador austríaco "colérico" se transformaria assim num "britânico enervado" que representa certo "ennui temperado pelas restrições sintáticas da língua inglesa" (HONEGGER 2010: 170). Ou seja, o narrador adquire outro formato, sem perder sua posição de "estrangeiro", de outsider, que Bernhard e seus narradores e personagens ocupam mesmo dentro do universo de língua alemã. Em relação às traduções de outro romance de Bernhard, Holzfällen (Árvores abatidas), HoNEGGER menciona que, mesmo a tradução inglesa tendo convertido o narrador num sujeito mais “conversador" e mais "racional”, o programa de correção gramatical automática do seu computador não reconhece a versão inglesa como normativamente "correta" (2010: 171), o que também evidenciaria o estatuto de "estrangeiro" do narrador dentro da língua inglesa. No seu artigo, HoNEGGER analisa e compara várias soluções de dois tradutores de Bernhard para a língua inglesa e chega à conclusão de que, enquanto uma versão sugere a "maestria estilística de Bernhard", a outra representaria melhor o "caráter" do personagem (2010: 181). Na análise da teórica, a comparação entre diferentes traduções torna-se assim tão, se não mais, importante do que a comparação das traduções com o texto original. Partimos desse olhar para nossa argumentação no presente trabalho - um olhar que se aproxima também da perspectiva de Peter UTZ, isto é, de que uma análise de diversas traduções de uma obra para uma mesma língua pode ser reveladora em relação ao próprio original: "Sobretudo onde as traduções divergem uma da outra, encontra-se uma ambiguidade no texto de partida, um ponto que necessita de interpretação, onde se revela sua legibilidade múltipla" (2007: 16). No universo brasileiro dos estudos da tradução, perspectivas semelhantes transparecem em trabalhos de Émile AUDIGIER (2009), Marie Hélène Catherine Torres (2009) e Maurício Mendonça CARdOZO (2012), para citar apenas alguns. Uma referência teórica importante para esses pesquisadores é o filósofo francês Antoine BERMAN (2007) e sua proposta de um método de análise de tradução e sua crítica sistemática do que chama tradução etnocêntrica e hipertextual. 


\section{Bohunovsky, R. - Perturbação}

Partindo desse contexto, de um grande leque de possíveis interpretações e de uma postura mais positiva em relação às diferenças de leitura da obra de Thomas Bernhard em âmbitos que não sejam de língua alemã, o objetivo deste trabalho é discutir alguns aspectos estéticos significativos da linguagem de Thomas Bernhard num dos seus romances (Verstörung, primeira publicação em alemão em 1967) e as estratégias usadas em relação a tais aspectos em duas traduções do romance para o português, numa versão publicada em Portugal (1986, tradução de Leopoldina Almeida) e outra no Brasil (1999, tradução de Hans Peter Welper e José Laurenio de Melo), ambas intituladas Perturbação. Entendemos por "aspectos estéticos significativos" aqueles que, talvez de uma maneira mais clara que outros, podem ser vistos não "apenas" como importantes para se perceber o estilo linguístico do texto, mas que produzem um efeito que pode interferir na interpretação que o leitor faz do texto.

Ao entender facetas formais como significativas, coloca-se em questão a validade do princípio da prosa "rem tene, verba sequentur" (ECO 2011: 57). Essa suposta predominância do conteúdo, do enredo, de uma obra em prosa, em detrimento da importância da sua forma, revela-se controversa especialmente em obras inovadoras na esfera estética. Para ilustrar essa afirmação, permito-me citar aqui algumas reflexões de Berthold ZILLY que, numa entrevista recente na qual comenta acerca do seu atual trabalho de retraduzir o Grande Sertão: Veredas para o alemão, critica a tradução já existente dessa obra, feita por Curt Meyer-Clason (1964). De acordo com ZILLY, Meyer-Clason produziu um texto "bem legível, muito bonito e bem-sucedido à primeira vista" (2012: 6), mas no qual se perdeu a "qualidade diferencial estilística", isto é, a distância entre o estilo do autor e o estilo convencional da época. Sendo o Grande Sertão uma obra cujo significado e cuja originalidade está em grande medida na sua forma, na sua poesia, a questão formal ganha destaque nas discussões sobre a sua tradução para diversas línguas. Assim, é justamente a qualidade estilística da já existente tradução alemã que justifica, no entender de Zilly, uma nova tradução. Nela, tentar-se-á "dar uma ideia da singularidade e da dificuldade do estilo original, além da qualidade diferencial deste estilo". No nosso entender, poder-se-ia levantar a hipótese de que talvez seja justamente o crescente prestígio da literatura roseana em contexto europeu que permita agora uma tradução mais próxima à "qualidade diferencial estilística" do original. 


\section{Bohunovsky, R. - Perturbação}

A questão do estilo parece importante também em discussões sobre traduções de Thomas Bernhard. Por exemplo, Miguel SÁEnZ, tradutor espanhol de Bernhard, comenta sobre o conflito que sentiu entre, por um lado, realizar o movimento de "polir, de banalizar, de simplificar" as "construções quase grotescas" da linguagem do original para "melhorar a legibilidade do texto", e assim atender aos pedidos da editora, e, por outro, procurar não perder o estilo do autor (1995: 88). Miklós GYÖRFFY, tradutor para o húngaro de livros de Bernhard, também destaca o papel fundamental da forma linguística, do estilo, desse autor, e resume que traduzir Bernhard significaria, sobretudo, enfrentar "uma construção linguística" que representa, "ela mesma, a mensagem literária" (1995: 92). A linguagem de Bernhard seria "uma construção linguística abstrata" que se refere "apenas tangencialmente a objetos ou conteúdos" que existiriam fora da obra literária. Entre os meios linguísticos que Bernhard utiliza para produzir essa construção, GYÖRFFY destaca - como muitos outros teóricos que refletem sobre a singularidade da linguagem de Bernhard - as complexas construções sintáticas, as repetições, o discurso indireto, termos compostos inusitados, assim como os exageros através de superlativos, insultos e a falta de argumentos para justificar suas avaliações (em geral extremamente negativos) (1995: 92). Sem se referir especificamente ao livro Perturbação, o tradutor húngaro dá indícios sobre a linguagem de Bernhard que são úteis também para a nossa reflexão:

As figuras de Bernhard sofrem pelo fato de que a linguagem é insegura e está em risco. Elas procuram, portanto, firmá-la e fazem isso explorando ao máximo as possibilidades significativas dessa linguagem. Assim nascem os trechos que parecem vir de um viciado em escrever, os monólogos intermináveis, as frases repletas de termos repetidos várias vezes e que serpeiam sem fim. [...] A loucura surge justamente com essa recorrência não racional. (GYÖRFFY 1995: 93).

A seguir, nos detemos mais detalhadamente na linguagem do livro Verstörung e suas traduções para o português. Nosso objetivo não é avaliar o grau de alguma suposta "fidelidade" das versões em relação ao "original". Entendemos as duas traduções como exemplos dos diversos "ecos" da obra de Bernhard no mundo, relevantes para entender a "linguagem universal de Bernhard" (BAYER 1995: 10). São ecos que, por um lado, podem ser entendidos como reflexos dos desdobramentos da teoria e crítica em relação à obra de Thomas Bernhard, mas que, por outro, podem marcar ou influenciar eles mesmos as discussões teóricas. 


\section{A Perturbação, de Thomas Bernhard, e sua tradução para o português}

Perturbação (Verstörung) não é apenas o título de um dos nove romances de Thomas Bernhard, é também o termo que melhor resume o efeito da sua obra inteira, sobretudo nos países de língua alemã. Numa colocação contra a tentativa de classificar Bernhard, mais de 20 anos após sua morte, como um clássico já sem potencial crítico, Sepp SCHELLHORN - num festival em homenagem de Thomas Bernhard que leva justamente o nome "Verstörungen" (Perturbações) - argumenta que a obra desse autor continua sendo uma "perturbação do pensamento tradicional, perturbação de qualquer ideologia filosófica, psicológica ou sociológica, perturbação de qualquer concepção que entende a literatura como algo esgotável pela interpretação" (2012: 2). Segundo Marcel REICHRANICKI, perturbação seria justamente aquilo que faz a obra de Bernhard incomensurável (apud SCHELLHORN 2012). Na própria Áustria, a recepção da obra de Bernhard, sobretudo nos primeiros anos, foi marcada por um efeito perturbador restrito frequentemente à dimensão política dos seus textos; já em outros países, essa faceta política não se revela tão fundamental. Assim, fora do contexto austríaco, a estrutura estética da obra de Bernhard ganhou maior importância e ficou em primeiro plano, evidenciando que não deve se limitar a visão sobre Bernhard como sendo apenas um escritor com pendor por provocações políticas, como foi feito pela crítica austríaca durante algum tempo, mas como um perturbador também no plano estético. Sobre o seu papel de perturbador, o próprio BERNHARD comenta, num dos seus escritos autobiográficos, com o exagero e as repetições de costume:

\footnotetext{
Minha existência sempre perturbou, o tempo todo. Sempre perturbei e sempre irritei as pessoas. Tudo que escrevo, tudo que faço é perturbação e irritação. Minha vida inteira, toda a minha existência nada mais é do que perturbação e irritação ininterruptas. Porque chamo a atenção para fatos perturbadores e irritantes. Existem aqueles que deixam os outros em paz e aqueles que perturbam e irritam, categoria à qual pertenço. Não sou do tipo de pessoa que deixa os outros em paz, nem quero ser uma pessoa assim. (2006: 241).
}

O efeito perturbador ilustra uma das facetas da dimensão performativa da linguagem bernhardiana. Por um lado, tal dimensão pode ser associada aos efeitos políticos causados 
Bohunovsky, R. - Perturbação

pelos seus textos. Nesse sentido, HonEGGER lembra que os textos de Bernhard são todos "atos de um performer solo", seus "efeitos performativos únicos dentro da vida cultural austríaca refletem o drama da autodefinição do país depois de 1945" (2003: 21). Performativa é, num segundo momento, também a gramática bernhardiana - agora no sentido linguístico, de locuções que, em vez de poderem ser falsas ou verdadeiras, criam uma realidade, produzem as condições de ser através da enunciação. Como aponta WEBBER:

\begin{abstract}
A voz idiossincrática de Bernhard está ligada unicamente a este modo de expressão. Em seus textos, os falantes estão sempre buscando estabelecer um estado de coisas acima de qualquer dúvida ou obter um diferente estado de coisas através de seus atos de fala. Enquanto o primeiro modo de discurso teatral ou histriônico parece corresponder ao que a teoria dos atos de fala chamaria de constatativo, mais do que performativo, aqui a constatação se imiscui com a performatividade; [o discurso] torna-se performativo em ambos os sentidos da palavra, teatral e linguístico. Quando o discurso constatativo é marcado pelo excesso de enunciação, isto é, através de formulações hiperbólicas ou repetitivas, ele se projeta na performatividade. (2010: 150).
\end{abstract}

É nesse sentido que nos referimos ao caráter performativo da linguagem bernhardiana. As repetições que marcam sua obra não têm o efeito de realçar traços da realidade, mas se tornam independentes dela e criam um mundo artificial, intensificando-se na medida em que a narrativa progride. Em Extinção, outro romance de Bernhard, o narrador oferece uma possível explicação para tal movimento: "Para o divertimento meu e de Gambetti, recitei várias vezes frases de Schopenhauer, [...] e as depositei, por assim dizer, [...] na balança das minhas mãos, e disso fiz gradualmente um jogo levado ao exagero" (BERnhard 2000: 9). Tal "jogo levado ao exagero" ou a "recorrência dos mesmos sentimentos ou pensamentos" pode "acabar por significar algo por si só", como observa Rüdiger GÖRNER (2010: 93-94). No caso de Verstörung, tal “jogo” exagerado é uma das ferramentas para atingir um efeito perturbador.

$\mathrm{O}$ romance divide-se em duas partes: na primeira, mais curta e narrativamente mais convencional, o narrador, filho de um médico rural na província austríaca da Estíria, relata como acompanha seu pai em suas visitas a doentes ou vítimas de violência nas suas respectivas casas. A segunda parte do livro é a reprodução de um monólogo do último paciente a ser visitado pelo narrador e seu pai: o príncipe Sarau, que reside no castelo de 


\section{Bohunovsky, R. - Perturbação}

Hochgobernitz e é a personificação da perturbação mental. Os dois personagens, pai e filho - este último também o narrador -, tornam-se aqui absolutamente secundários, eles cumprem apenas a função de serem os destinatários do monólogo do príncipe.

O narrador de Verstörung é um observador que se limita a contar alguns fatos e acontecimentos em relação às visitas aos doentes, aparentemente sem interpretá-los, e cuja função principal é reproduzir a fala dos outros personagens, seja em discurso indireto ou direto ${ }^{4}$. Tal narrador-observador é recorrente na obra de Bernhard, porém em outros livros assume uma posição mais central, por exemplo, em Holzfällen (Árvores abatidas), onde o narrador relata principalmente seus próprios pensamentos ao observar um grupo de artistas durante um jantar. Em Verstörung, o narrador cita apenas as falas dos outros personagens e, na segunda parte do livro, se limita quase exclusivamente a reproduzir a fala do príncipe Sarau. É interessante notar que Bernhard usa, ao longo do livro todo, praticamente apenas o termo "sagen" (dizer) para indicar um discurso direto, causando um efeito artificial e até cômico pela alta incidência desse verbo, que encontramos em quase todas as páginas do livro:

[...] Aber überhaupt, sagte ich doch”, sagte der Fürst, ,ich sagte, lächerlich, das zu sagen, überhaupt hatte ich den Eindruck, daß der Mann seine Kräfte überschätzte. Sie überschätzen Ihre Kräfte bei weitem! sagte ich, und Zehentmayer setzte dem, was ich sagte... (BERNHARD 1979: 79, ênfase minha).

Nas duas traduções discutidas neste artigo, a recorrência do verbo "dizer" é alta, porém quebrada frequentemente por verbos alternativos como contar, continuar, prosseguir, pronunciar, gritar, julgar, acrescentar, confirmar etc., o que resulta numa aproximação às convenções estilísticas de um texto narrativo, segundo as quais seria preferível evitar a exagerada repetição de um mesmo termo.

\footnotetext{
${ }^{4}$ Em alemão, o discurso indireto é indicado pelo tempo verbal do Konjunktiv I ou do Konjunktiv II, recursos linguísticos usados abundantemente por Bernhard e que tornam desnecessária a colocação repetida de fórmulas inquit (ele disse) para distanciar o narrador daquilo que é citado. A inexistência desse tempo verbal em português obriga o tradutor ou a aumentar ainda mais o número de intercalações como "ele disse" (tornando o texto "mais bernhardiano" do que o original [SÁENZ 1995: 87]) ou a mudar a posição do narrador ao usar um tempo verbal no indicativo. Sem me aprofundar nessa questão aqui, quero, porém, mencionar que, por causa das soluções escolhidas pelos tradutores de Verstörung, o narrador assume posições diversas nas versões portuguesa e brasileira. Desse modo, um aspecto gramatical revela-se altamente significativo.
} 


\section{Bohunovsky, R. - Perturbação}

Como em todas as obras fictícias de Thomas Bernhard, sejam elas dramáticas ou de prosa, o enredo de Perturbação pode ser resumido em poucas palavras. Entretanto, como já apontou Wendelin SCHMIDT-DENGLER, resumir o enredo das narrações bernhardianas não contribui muito para uma compreensão da sua linguagem ou para uma aproximação com o seu texto: apenas se reconheceria motivos e situações semelhantes que são relevantes, porém incompreensíveis sem uma análise das reflexões que ocupam um lugar predominante em toda a obra em prosa de Bernhard (SCHMIDT-DENGLER 2010: 11). O monólogo do príncipe Sarau em Verstörung é o exemplo mais famoso desse enfoque reflexivo do autor, que se autodenomiou certa vez como um "destruidor de histórias", e ilustra também porque Bernhard é comparado muitas vezes a Samuel Beckett (enquanto não se encaixa de modo algum na tradição ensaística de outro austríaco famoso, Robert Musil). No monólogo do príncipe, citado pelo narrador, "a reflexão contínua praticamente anula a ação" (SCHMIDT-DENGLER 2010: 11). A fala do príncipe não constitui uma narrativa ou argumentação coerente (embora inclua algumas passagens de caráter narrativo). Trata-se muito mais de um compêndio de reflexões aparentemente incoerentes, no qual se podem perceber certos conceitos e temas centrais como a morte, a vida, a natureza e a ciência - frequentes, aliás, em toda a obra de Bernhard. A perturbação do príncipe Sarau manifesta-se não apenas no conteúdo temático das suas reflexões, mas também e, sobretudo, na sua linguagem. De acordo com o próprio Bernhard, ele procurou iniciar essa obra de uma maneira narrativa "clássica", para depois levar o leitor cada vez mais para dentro do "horror" (apud HubER; SCHMIDT-DENGLER 2008: 780). Nesse sentido, o monólogo do príncipe Sarau exerce uma função paradigmática na obra de Bernhard, e o caráter radical e de exclusão (Ausschließlichkeit) da sua linguagem se mostra de maneira muito clara (SCHMIDT-DENGLER 2010: 11). A construção da personagem do príncipe Sarau não se dá através de passagens descritivas, mas exclusivamente pela reprodução da sua fala, que só pode ser definida como perturbada e perturbante para o leitor, com construções sintáticas altamente complexas e impossíveis de serem decifradas numa leitura fluente, com colocações hiperbólicas, paradoxais, ambíguas, agramaticais e repletas de recursos retóricos.

Passemos então a alguns trechos exemplares da obra que evidenciam decisões divergentes dos tradutores frente a tais aspectos linguísticos e estilísticos. Como já foi 


\section{Bohunovsky, R. - Perturbação}

mencionado, a primeira parte do livro pode ser lida como uma constante aproximação à perturbação, à loucura que espera o narrador e seu pai no castelo Hochgobernitz na segunda parte do livro. Essa aproximação à loucura manifesta-se em vários níveis. Por exemplo, no espaço geográfico representado na obra e no caráter estilístico da linguagem dessa primeira parte mais narrativa e convencional, mas em que já se pode perceber claramente, a inconfundível estética tão típica de Bernhard. Vejamos a primeira frase do livro, no original e nas duas traduções:

Am 26. fuhr mein Vater schon um zwei Uhr früh zu einem Lehrer nach Salla, den er sterbend angetroffen und als Toten gleich wieder in Richtung Hüllberg verlassen hat, um dort ein Kind zu behandeln, das im Frühjahr in einen mit siedendem Wasser angefüllten Schweinebottich gefallen und jetzt schon wieder wochenlang, aus dem Spital entlassen, zu Hause bei seinen Eltern war. (BERNHARD 1979: 7).

Tradução portuguesa (Leopoldina Almeida):

No dia 26, logo às duas horas da manhã, o meu pai meteu-se a caminho para ir visitar um professor primário em Salla, que foi encontrar já moribundo, e que veio a morrer logo após a sua chegada. Voltou então a sair, e partiu para Hüllberg para ir tratar de uma criança que na Primavera tinha caído numa pia de porcos cheia de água a ferver e que, após ter estado internada algum tempo no hospital, estava já há algumas semanas em casa dos pais. (BERNHARD 1986: 7).

Tradução brasileira (Hans Peter Welper e José Laurenio de Melo):

No dia 26 meu pai saiu às duas da madrugada para visitar em Salla um professor que encontrou moribundo e deixou já morto, voltando a sair em seguida para Hüllberg, a fim de tratar ali de um menino que, na primavera, tinha caído numa gamela cheia de água fervendo e que agora, tendo recebido alta do hospital, estava há várias semanas em casa com os pais. (BERNHARD 1999: 1).

Quero chamar atenção para dois aspectos dessa passagem em alemão: sua construção sintática e o foco narrativo no pai. Embora não se trate de uma das sentenças mais típicas de Bernhard - que se estendem por muitas linhas e até mais de uma página -, a sua construção ilustra o estilo peculiar do autor, que junta várias frases e intercalações de modo pouco convencional. E um olhar para as traduções já revela estratégias muito diversas ao lidar com sua forma sintática. Enquanto a versão portuguesa transforma o parágrafo em duas sentenças separadas por um ponto final que deixa o leitor "respirar", 
Bohunovsky, R. - Perturbação

na tradução brasileira procura-se manter a complexidade sintática. $\mathrm{O}$ foco narrativo no pai causa, no texto alemão, uma imagem insólita, pois um acontecimento tão importante como a morte de uma pessoa, no caso do professor, é apenas comentado como um acontecimento absolutamente corriqueiro. O que está em primeiro plano é o pai que deixa alguém que morreu. Na versão portuguesa, o foco muda, pois, ao morrer, o professor torna-se sujeito da frase, aproximando-a, ao mesmo tempo, da forma de um relato convencional sobre a morte de alguém. A simplificação da estrutura sintática e a aproximação a formas convencionais de narrativa, na tradução portuguesa, e a procura de não aderir a tais estratégias, na tradução brasileira, podem ser entendidas, neste primeiro momento, como indícios de duas posturas de interpretação bastante diferentes nas duas versões aqui discutidas.

Na segunda parte do livro - quase inteiramente a reprodução do monólogo do príncipe Sarau - as duas posturas se evidenciam de forma mais clara. Cito a seguir uma passagem - e suas traduções - na qual tanto o conteúdo temático quanto a própria forma indicam a perturbação do príncipe:

Sich mehr und mehr seiner auf die „höhere Exaltation und auf die höhere Spekulation konzentrierenden Geistesmechanik" (Vater) fügend, in seinen Schwächezuständen, selbst in dem ihm im Laufe der letzten Monate zur unerträglichsten aller Qualen gewordenen Zustand in seinen von ihm ganz allein mit sich selber in seinem festverriegelten Zimmer geführten ,masochistischen Diskussionen“ (Vater), die er auch während des Englandaufenthaltes seines Sohnes nicht unterbrochen und, wahrscheinlich aus der Tatsache heraus, bis an sein Lebensende in Hochgobernitz existieren zu müssen, mit der größten Rücksichtslosigkeit vor allem gegen sich selbst in eine Höhe gelenkt hat, die, auf die infame Irritation konzentriert, die äußerste Anspannung seines Geistes erfordert, eine immer noch rücksichtslosere Anspannung seines Geistervermögens, „folgerichtig in alle naturwissenschaftlichen Phänomene hinein“ (Sarau), habe er diese für ihn „tödlichen Geräusche“ (Vater), auch während er in der vergangenen Nacht die Memoiren des Kardinal Retz studiert hat, gehört, „hören müssen“, erinnerungsunfähig, was den Zeitpunkt, von welchem er diese Geräusche anzuhören gezwungen sei, betrifft. (BERNHARD 1979: 102).

Tradução portuguesa (Leopoldina Almeida):

Entregando-se cada vez mais a "um mecanismo de espírito concentrado na maior exaltação e na mais funda especulação" (no dizer do meu pai), nos seus acessos da fraqueza o estado de saúde do príncipe agravava-se nos últimos meses a ponto de sentir dores insuportáveis; mantinha "discussões masoquistas" 
Bohunovsky, R. - Perturbação

(assim dizia o meu pai), completamente sozinho e fechado a chave no quarto, mesmo durante a estada do filho em Inglaterra. Talvez pelo facto de ter de viver até ao fim dos seus dias em Hochgobernitz, lutara impiedosamente, sobretudo consigo próprio, tentando vencer essa atroz exasperação, e essa luta exigira do seu espírito um esforço tremendo, e um esforço ainda mais impiedoso das suas capacidades de espírito para "penetrar de forma lógica em todos os fenômenos das ciências da natureza" (assim dizia o Sarau). "Começara então a ouvir esses barulhos fatais" (dizia o meu pai) "era obrigado a ouvi-los", e não conseguia lembrar-se a partir de que altura tinha começado a ouvi-los; ainda na noite anterior os ouvira enquanto estudava as memórias do Cardeal Retz. (BERNHARD 1986: 126).

Tradução brasileira (Hans Peter Welper e José Laurenio de Melo):

O príncipe, submetido cada vez mais à sua "mecânica intelectual centrada na alta exaltação e na alta especulação" (meu pai), em seus estados de debilidade, incluído aquele estado que se tinha convertido nos últimos meses no mais insuportável dos tormentos, por suas "discussões masoquistas" (meu pai) consigo mesmo - trancado com ferrolho em seu próprio quarto -, que não havia interrompido durante a estada de seu filho em Londres e que, provavelmente porque teria de viver até o fim de seus dias em Hochgobernitz, levara - da maneira mais impiedosa, sobretudo para si mesmo - a um paroxismo que, centrado numa irritação abjeta, exigia o máximo esforço de sua mente, um esforço cada vez mais brutal de sua capacidade intelectual, "orientado de forma conseqüente para todos os fenômenos científicos" (príncipe Sarau), ouvira, "tivera que ouvir", esses "ruídos mortais" (meu pai) para ele, até enquanto, na noite passada, estudava as memórias do Cardeal de Retz, embora fosse incapaz de recordar o momento em que começara a ouvir tais ruídos. (BERNHARD 1999: 116).

No texto alemão, temos uma longa passagem em que sujeito e verbo flexionado encontram-se quase no final do período (habe er [...] gehört) sendo precedidos por um complexo sistema de frases subordinadas e atributos antepostos cuja análise detalhada tomaria boa parte deste artigo. Seu efeito é aquilo que os críticos têm chamado a "linguagem vertiginosa", ou, nas palavras de Cristóvão TEZZA, seria o "nocaute inesquecível" da literatura de Bernhard (apud CASTELlo 2012). É o exemplo de uma passagem tipicamente bernhardiana para cuja elaboração o autor recorre a inúmeras construções sintáticas inusitadas. Trata-se de uma das muitas passagens do livro que vai até os limites das possibilidades linguísticas do alemão e nas quais o leitor mergulha e emerge exausto no final. Na versão portuguesa, a mesma passagem é dividida em várias frases principais, tendo cada uma, no mínimo, um verbo flexionado (a saúde agravavase, mantinha discussões, lutara, essa luta exigira, começara, não conseguia, ouvira). $\mathrm{Na}$ 


\section{Bohunovsky, R. - Perturbação}

voz do narrador, apresenta-se aqui um relato sensato, bem articulado e bastante convencional dos distúrbios mentais do príncipe. A construção sintática da frase não retrata nem causa estranhamento ou perturbação no leitor. A perturbação aparece apenas naquilo que é retratado. Já na versão brasileira, percebe-se um esforço maior dos tradutores para levar o leitor, o máximo possível, até as peculiaridades estilísticas da linguagem bernhardiana. O português é trabalhado e adaptado ao extremo dentro dos seus limites, emprega-se uma construção sintática nada usual, porém possível dentro da língua. Recorre-se frequentemente aos travessões para elaborar essa construção complexa - recurso bastante comum em traduções de Bernhard para outras línguas.

Além de construções sintáticas extremas, outra característica da linguagem de Thomas Bernhard é o uso frequente do superlativo e de expressões, atributos e advérbios que remetem à totalidade, que não permitem qualquer exceção às afirmações feitas. (ganz, in jedem Fall, fortwährend, ununterbrochen etc. Na citação acima: ganz, immer). De acordo com SCHMIDT-DENGLER, tais expressões, que impossibilitam qualquer relativização, assim como os superlativos de Bernhard, estão estreitamente relacionadas ao processo de tornar absoluta qualquer caracterização de um lugar, uma situação, um personagem - movimento relacionado à postura filosófica de Bernhard e muito frequente em sua obra (2010: 12-13). Na passagem citada acima, temos três adjetivos na forma de superlativos (unerträglichsten, größten, äußerste). No entanto, apenas na versão brasileira mantém-se o caráter absoluto dos adjetivos usados - que aparentemente não permite uma relativização daquilo que é afirmado. Há uma evidente diferença de intensidade entre a expressão "unerträglichsten aller Qualen”, que consta no original, e “dores insuportáveis", da versão portuguesa. Em nossa leitura, com a escolha da tradução "mais insuportável de todos os tormentos", a versão brasileira procurou manter o caráter radical e absoluto da expressão alemã.

Para ilustrar com mais um exemplo as posturas de interpretação nas duas traduções, nos referimos a uma frase curta que também consta na segunda parte de Perturbação. Ao narrar uma conversa que teve com um candidato a emprego no castelo Hochgobernitz, o príncipe faz a seguinte observação:

Stumpfsinnig mechanisch bewegt er die ganze Zeit, mir gegenübersitzend, seine Bewegungslosigkeit. (BERNHARD 1976: 82) 
Bohunovsky, R. - Perturbação

Tradução portuguesa (Leopoldina Almeida):

Sentado na minha frente, agitava-se continuamente, interrompia a forçada imobilidade com movimentos estupidamente mecânicos. (BERNHARD 1986: 102)

Tradução brasileira (Hans Peter Welper e José Laurenio de Melo):

Sentado de frente para mim, equilibrava sua imobilidade de um modo estupidamente mecânico. (BERNHARD 1999: 92)

O leitor do texto alemão vê-se confrontado com um paradoxo (alguém movimenta a sua imobilidade) que extrapola a lógica comum. Já na versão portuguesa, o caráter paradoxo do trecho é eliminado, a imobilidade é "interrompida" com "movimentos mecânicos", uma interpretação que corresponde ao senso comum no que diz respeito à impossibilidade de algo se mover enquanto está imóvel. Pode-se afirmar que a tradutora portuguesa seguiu a colocação de Hans-Georg GADAMER de que qualquer tradução deveria ser um "esclarecimento enfatizante" (apud ECO 2011: 119), de que o tradutor "não pode deixar em suspenso nada que não lhe pareça claro", sobretudo nas passagens em que algo seja "obscuro" também para o "leitor 'originário"”. De acordo com GADAMER, "toda tradução que leve a sério a própria tarefa resulta mais clara e mais superficial que o original” (apud ECO 2011: 119). Já na tradução brasileira, o personagem "equilibra" sua imobilidade, uma colocação menos convencional que lembra a ambiguidade da frase em alemão. Os tradutores parecem ter seguido aqui a sugestão de Eco que diz respeito a casos em que "o autor (e o texto) eram e queriam permanecer ambíguos, precisamente para suscitar uma interpretação oscilante" (EcO 2011: 120). Nesses casos, Eco opina que "o tradutor deve reconhecer e respeitar a ambiguidade, e fará mal em esclarecê-la" (id.).

Com essas observações, não temos o objetivo de classificar alguma tradução como "errada", pois todas as traduções citadas neste artigo são possíveis e justificáveis a partir do texto de partida ${ }^{5}$. A ambiguidade da frase em alemão e sua simplificação pela

\footnotetext{
${ }^{5} \mathrm{Na}$ análise das duas traduções, encontramos, em ambas, termos ou frases que foram traduzidos de maneira errada, ou seja, não são justificáveis a partir do texto original (Apenas um exemplo da cada tradução: “[...]
} 
Bohunovsky, R. - Perturbação

tradutora portuguesa se aproximam da seguinte situação descrita por R. A. BEAUGRANDE: "É compreensível que poetas estejam inclinados a velar seus significados, e tradutores instintivamente sintam ambições de finalizar estes significados prematuramente" (apud WEININGER 2012: 202). Embora Beaugrande se refira aqui à tradução de poesia, sua afirmação parece válida com respeito às passagens da tradução portuguesa aqui citadas. Os tradutores brasileiros, por outro lado, seguiram o caminho sugerido por Markus WEININGER, que considera que, em casos de ambiguidade semântica no texto de partida, "parece interessante manter na tradução um leque aberto de possíveis interpretações" (2012: 202). Esse seria também o caminho indicado por Eco, que vê a ambiguidade como aquilo que justamente pode tornar uma obra literária fascinante e, portanto, como algo que deve ser recriado de uma maneira ou outra na tradução (ECO 2011: 67).

A partir dos poucos exemplos aqui citados, permitimo-nos levantar a hipótese de que as duas traduções focalizam, de um modo geral, duas dimensões diferentes de Verstörung. Enquanto a linguagem de Leopoldina Almeida possibilita um acesso mais direto ao conteúdo narrativo da obra, a tradução de Hans Peter Welper e José Laurenio de Melo aproxima-se mais das características estilísticas de Bernhard.

É interessante notar ainda que as duas posturas tradutológicas que identificamos nas versões portuguesa e brasileira de Verstörung refletem-se também nos paratextos dos dois livros. O único paratexto - além de nome de autor, de tradutor, título, informações bibliográficas e editoriais ${ }^{6}$ - que existe na versão portuguesa, é um pequeno texto na quarta capa. Nele não é feita nenhuma referência à linguagem ou ao estilo literário de Thomas Bernhard. Somos informados apenas que o livro trata "dos sentimentos de um jovem que em companhia do pai médico visita alguns doentes". Além da referência ao conteúdo do livro, lemos também que os aspectos temáticos centrais do livro seriam a obsessão pela morte, os

immer nur von der Hochgobernitz, der Burg, reden hören” (1967: 78), traduzido por: "[...] só ouvira falar do Hochgobernitz e do castelo" (1986: 97); "und ich schließe immer von mir [...] auf die ganze Welt usf." (1967: 116), traduzido por "e sempre excluo de mim" (1999: 133). Para a sustentação da nossa argumentação acerca de divergentes estratégias de tradução e suas possíveis consequências na leitura da obra em uma versão em outra língua, tais erros são, porém, de menor importância e não serão abordados aqui.

${ }^{6}$ Para uma discussão sobre paratextos, cf. GENETTE (2001). 


\section{Bohunovsky, R. - Perturbação}

[...] náufragos de um mar imóvel, a Áustria que [Thomas Bernhard] cobriu de imprecações, seres que bordejam uma loucura que lhe permite desfazer as aparências do mundo, como no caso desse príncipe que sonha os seus domínios destruídos pelo filho que os vai herdar. (BERNHARD 1986, texto da quarta capa).

Se relacionarmos esse paratexto às nossas reflexões sobre a tradução de certos aspectos formais da linguagem de Bernhard na versão portuguesa, reforçamos nossa avaliação de que o foco dessa tradução é comentar o conteúdo factual, o enredo do livro. Na versão brasileira, o foco da tradução é outro - e isso se reflete também no paratexto "Prefácio", da autoria de Bernardo Ajzenberg. Já no primeiro parágrafo, AJZENBERG anuncia ao leitor mais um livro da "prosa demoníaca" (in BERnhARD 1999: VII) de Bernhard. Ajzenberg destaca que "a literatura de Thomas Bernhard [...] independe dos seus enredos", pois "uma rede invisível" onde "se misturam filosofia, loucura, suicídio, política, doença - e, sobretudo, a energia da linguagem e seus impasses" (id.) estaria em primeiro plano, num texto que teria "algo de vertiginoso" (id.). O prefaciador menciona também a relação da obra de Bernhard com a filosofia de Schopenhauer, Nietzsche e Wittgenstein, dá algumas informações sobre o enredo e chega à conclusão de que "o mote permanente do discurso de Sarau é a impossibilidade de se comunicar com os outros, de fazer-se compreender" (id.: IX). Encerra o prefácio a observação de que esse livro teria sido escrito em "uma linguagem de terra arrasada, verdadeiramente perturbadora" (id.: X). A tradução que Hans Peter Welper e José Laurenio de Melo fizeram de Verstörung só corrobora e ilustra tais afirmações. Podemos resumir que nas duas publicações de Verstörung em língua portuguesa, os textos traduzidos e os referidos paratextos complementam-se coerentemente e apresentam duas Perturbações diferentes.

\section{Conclusão}

Vários autores e tradutores têm se debruçado sobre a dificuldade de traduzir a literatura de Thomas Bernhard e têm apontado algumas características de sua linguagem como as que representam os maiores obstáculos para os tradutores, quais sejam: o alto índice de neologismos, a recorrência de certos termos chave, seu uso criativo das especificidades morfológicas da língua alemã, a musicalidade etc. (Cf., por exemplo, os artigos de SÁENZ 


\section{Bohunovsky, R. - Perturbação}

(1995), GYÖRFFY (1995), BERNARDI (1995) e a tese de doutorado de BÖHLER (2002). No presente artigo, abordando Verstörung, nos limitamos a alguns desses aspectos formais da linguagem de Thomas Bernhard que consideramos relevantes para a produção do efeito perturbador de sua obra. As opções dos tradutores ao verter o livro para o português podem ser oriundas de decisões e interpretações individuais ou editoriais, mas, podem ser vistas também como condizentes com as leituras predominantes nas respectivas épocas nas quais foram feitas.

Depois da discussão de alguns trechos e suas traduções para o português, concluímos que a tradução portuguesa e a brasileira partiram de duas "hipóteses de interpretação" diferentes. A tradução portuguesa tem seu foco no enredo, nos traços narrativos da obra e facilita o acesso do leitor a esse conteúdo. Realizou-se uma tradução que amenizou a dimensão performativa da obra, no sentido acima definido. Desse modo, essa tradução pode ser vista como um exemplo da recepção e da crítica predominante nos anos 1980, ainda concentrada no suposto caráter mimético dos textos no que diz respeito à realidade do Estado da Áustria. Considerando o fato de que a tradutora Leopoldina Almeida recebeu, em 1988, o Grande Prêmio de Tradução Literária de Portugal, justamente pela tradução da obra Der Untergeher (O náufrago), também de Thomas Bernhard, é lícito supor que a tradução de Verstörung também tenha sido recebida de modo positivo pela crítica. O foco no enredo da obra é expresso também no pequeno paratexto que se encontra na quarta capa do livro - fato que sustenta a avaliação aqui exposta. A perturbação da personagem do príncipe é representada através de uma linguagem mais convencional, racional e acessível do narrador.

Já a tradução brasileira de Hans-Peter Welper e José Laurenio de Melo criou um texto cujo objetivo principal seria produzir aquilo que a crítica mais recente tem destacado como fundamental para definir o singular da linguagem bernhardiana, as difíceis construções sintáticas, a alta frequência do superlativo, assim como o caráter absoluto das afirmações - enfim, todas as ferramentas que foram apontadas, sobretudo a partir dos anos 1990, como relevantes para produzir o efeito perturbador, a dimensão performativa, da obra. Assim, a partir de uma perspectiva correspondente à crítica acadêmica mais recente, a tradução brasileira se aproxima da definição de uma tradução documental, e, mais especificamente, de uma tradução "filológica", no sentido dado por 


\section{Bohunovsky, R. - Perturbação}

Christiane NORD (2011). No entanto, essa avaliação guarda certo relativismo, pois tal tradução pode ser entendida também como sendo instrumental, já que na cultura de chegada se inscreve como um texto literário e perturbador por si só. A tradução é complementada por um prefácio que também dá destaque a aspectos formais da linguagem, definindo o enredo como de menor importância. Trata-se de uma tradução que teria como objetivo principal a produção de um texto performativo que desafie a língua de chegada, assim como o texto original faz no seu contexto de língua alemã. A perturbação manifesta-se aqui também na linguagem de um texto performativo - aspecto que torna a tradução mais condizente com a visão atual e predominante da crítica internacional sobre a literatura de Thomas Bernhard.

\section{Referências bibliográficas}

AjZEnberg, Bernardo. Prefácio. In: BERNHARD, Thomas. Perturbação. Trad. Hans Peter Welper e José Laurenio de Melo. Rio de Janeiro: Rocco 1999. p. VII- X.

AUDIGIER, Émile. Uma comparação de traduções de Guimarães Rosa para o francês. In: PIETROluongo, Márcia Atálla (org.). O trabalho da tradução. Rio de Janeiro: Contra Capa 2009. P. 133-146.

BAYER, Wolfram (Org.). Kontinent Bernhard: zur Thomas-Bernhard-Rezeption in Europa. Wien, Köln, Weimar: Böhlau 1995.

Berman, Antoine. A tradução e a letra ou o albergue do longínquo. Trad. Marie-Hélène Catherine Torres, Mauri Furlan, Andréia Guerini. Rio de Janeiro: 7Letras/PGET 2007.

BERNARDI, Eugenio. Der Übersetzer im Stahlschrank. In: BAYER, Wolfram (Org.). Kontinent Bernhard: zur Thomas-Bernhard-Rezeption in Europa. Wien, Köln, Weimar: Böhlau 1995. p. 100-108.

BERNHARD, Thomas. Verstörung. Frankfurt am Main: Suhrkamp 1979.

Bernhard, Thomas. Perturbação. Trad. Leopoldina Almeida. Lisboa: Relógio d’Água 1986.

Bernhard, Thomas. Perturbação. Trad. Hans Peter Welper e José Laurenio de Melo. Rio de Janeiro: Rocco 1999.

Bernhard, Thomas. Extinção. Uma derrocada. Trad. José Marcos Mariani de Macedo. São Paulo: Companhia das Letras 2000.

Bernhard, Thomas. Origem. Tradução de Sergio Tellaroli. São Paulo: Companhia das Letras 2006.

BÖHLER, Christiane. Literatur in der Übersetzung. Beispiel einer Evaluierung anhand Thomas Bernhards Roman Holzfällen. Eine Erregung. Universität Innsbruch 2002.

CARDOZO, Maurício Mendonça. Tradução como transformação: liminaridade, incondicionalidade e a crítica da relação tradutória. Revista Letras (Curitiba), v. 85 2012. p. 181-201.

CAstello, José. Cristóvão, o otimista 7 de fevereiro de 2012. Disponível em: <http://www.valor.com.br/cultura/2534500/cristovao-o-otimista>. (01/10/2 2012).

Eco, Umberto. Quase a mesma coisa. Experiências de tradução. Rio de Janeiro: BestBolso 2011. 
Bohunovsky, R. - Perturbação

GENETTE, Gérard. Paratexte - Das Buch vom Beiwerk des Buches. Trad. Dieter Hornig. Frankfurt am Main: Suhrkamp 2001.

GÖRNER, Rüdiger. The Broken Window Handle: Thomas Bernhard's Notion of Weltbezug. In: KonZETT, Matthias (Org.). A Companion to the Works of Thomas Bernhard. Nova York, Suffolk: Camden House 2010. p. 89-104.

GYÖRFFY. Mikós. Partitur und Instrument. Thomas Bernhard ungarisch spielen. In: BAYER, Wolfram (Org.). Kontinent Bernhard: zur Thomas-Bernhard-Rezeption in Europa. Wien, Köln, Weimar: Böhlau 1995. p. 91-99.

HoNEGGER, Gitta. Thomas Bernhard - "Was ist das für ein Narr”. Trad. Gitta Honegger. Munique: Propyläen 2003.

HonegGer, Gitta. Language Speaks. Anglo-Bernhard: Thomas Bernhard in Translation. In: KonZETT, Matthias (Org.). A Companion to the Works of Thomas Bernhard. Nova York, Suffolk: Camden House 2010. p. 169-186

Huber, Martin; SCHMIDT-DengLER, Wendelin. Umspringbilder: Romanwerk und Leben Thomas Bernhards. In: HubER, Martin; SCHMIDT-DENGLER, Wendelin (Org.). Thomas Bernhard: Die Romane. Frankfurt am Main: Suhrkamp 2008. p. 1769-1809.

KonZETT, Matthias (Org.). A Companion to the Works of Thomas Bernhard. Nova York, Suffolk: Camden House 2010.

LiSIECKA, Slawa. „Dankrede 8. Mai2012“. Disponível em: < http://eukstraelen.de/deutsch/uebersetzerpreis/slawa-lisieckauebersetzerpreis-2 2012/dankredelisiecka/index.html>. (30/11/2 2012).

MONOLOGE AUf MALLORCA + DiE URSACHE BIN ICH SELBST. Gespräche mit Krista Fleischmann. DVD, Suhrkamp 2008.

NORD, Christiane. Funktionsgerechtigkeit und Loyalität. Theorie, Methode und Didaktik des funktionalen Übersetzens. Berlin: Franck \& Timme Gmbh Verlag 2011.

PECKA, Zdeněk. Und wo bleibt der Witz? Humas als vergessener Aspekt der Bernhard-Rezeption. In: BOMBITZ, Attila et al. (Org.). Österreichische Literatur ohne Grenzen: Gedenkschrift für Wendelin Schmidt-Dengler. Viena: Praesens Verlag 2009.

RosA, Guimarães Rosa. Grande Sertão. Trad. Curt Meyer Clason. Köln, Berlin: Kiepenheuer und Witsch 1964.

SÁENZ, Miguel. Trastorno 'versus' Verstörung. In: BAYER, Wolfram (Org.). Kontinent Bernhard: zur Thomas-Bernhard-Rezeption in Europa. Wien, Köln, Weimar: Böhlau 1995. p. 83-90.

SCHMIDT-DENGLER, Wendelin. Der Tod als Naturwissenschaft neben dem Leben, Leben. Zu Bernhards Sprache der Ausschließlichkeit. In: SchMIDT-DENGLER, Wendelin. Der Übertreibungskünstler. Zu Thomas Bernhard. Wien: Sonderzahl 2010.

SCHELlHORN, Sepp. "Verstörungen - Ein Fest für Thomas Bernhard“. Disponível em: < http://www.derseehof.at/wp-content/uploads/2 2012/02/Verstoerungen1.pdf>. (30/11/2 2012).

TORRES, Marie Hélène Catherine. Tradução e retradução dos clássicos: análises do discurso de acompanhamento. In: Pietroluongo, Márcia Atálla (org.). O trabalho da tradução. Rio de Janeiro: Contra Capa 2009. p. 147-153.

UTZ, Peter. Anders gesagt, autremente dit, in other words. Übersetzt gelesen: Hoffmann, Fontane, Kafka, Musil. Munique: Hanser Verlag 2007.

WeBBer, Andrew. Costume Drama: Performance and Identity in Bernhard's Work. In: KonZETT, Matthias (Org.). A Companion to the Works of Thomas Bernhard. Nova York, Suffolk: Camden House 2010. p. 149-165.

WEININGER, Markus J. Algumas reflexões inevitáveis sobre a tradução da poesia. In: BLUME, Rosvitha Friesen; WeININGER, Markus J. Seis décadas de poesia alemã - do pós-guerra ao início do século XXI. Florianópolis: UFSC 2012. p. 193-216. 
Bohunovsky, R. - Perturbação

ZILLY, Berthold. Entrevista com Berthold Zilly. Disponível em: <http://verahelena.blogspot.com.br/2 2012/07/berthold-zilly-na-revista-metafora.html . (05/09/2 2012).

Recebido em 01/02/2013 Aprovado em 08/04/2013 